\title{
Strength Calculations of Dual-power Path Gearing with FEM
}

\author{
Jacek Pacana', Andrzej Pacana', Lucia Bednárová* \\ Rzeszow University of Technology, The Faculty of Mechanical Engineering and Aeronautics al. Powstańców Warszawy 8, 35-959 Rzeszów \\ 2 Ekonomická univerzita v Bratislave, Podnikovohospodárska fakulta v Košiciach, Tajovského 13, 04130 Košice
}

\section{BIOGRAPHICAL NOTES}

Andrzej Pacana, DSc, PhD, Eng., Associate Professor of the Rzeszów University of Technology. He is working in the Department of Technology and Production Engineering, at the Faculty of Mechanical Engineering and Aeronautics of the Rzeszów University of Technology. Author or co-author of 23 books and approx. 230 scientific papers published in national and international journals and presented at conferences. His scientific research interests include issues on: quality management systems, environmental and safety labor, logistics and quality engineering.

Jacek Pacana, PhD, Eng., Is a graduate of the Faculty of Mechanical Engineering and Aeronautics at the Rzeszów University of Technology. After graduation he worked in industry, and currently he is employed at the Department of Machine Design at the Faculty of Mechanical Engineering and Aeronautics of the Rzeszów University of Technology. His scientific research interests include issues related to the use of CAD / CAM / CAE methods in designing and mechanical design calculations, and gears in particular. His works within this scope were published in national and international journals and presented at many scientific conferences.

Lucia Bednárová, Doc. PhD, Ing., She is working as an Associate Professor on University of Economics in Bratislava, Faculty of Business Economy with seat in Košice. Author or co-author of 10 books and approx. 120 scientific papers Publisher in national and international journals and presented at conferences. Her scientific research interests include issues on: environmental and safety labor, logistics and process management.

\section{KEYWORDS}

Dual-power path gearing; calculations of strength, FEM, stress analysis.

\section{ABSTRACT}

The paper contains a strength analysis of gears in a dual-path gearing made of plastic. Calculations were carried out using Abaqus program by means of Finite Element Method (FEM). Due to the fact that the dual-path gearing had wheels with straight teeth, it was possible to simplify the calculations using two-dimensional models. In the carried out FEM analysis, stress distribution was determined on models of pinions and gears, paying particular attention to key points like teeth feet or their side surfaces. Conclusions obtained as a result of the analysis will make it possible to introduce conceivable changes in the structure of the designed gearing already at the stage of modelling. This will allow for significant time and financial savings in comparison to traditionally carried out experiments using physical models.

\section{Introduction}

Mechanical gears designing is carried out increasingly or even exclusively with use of computerized numerical methods. It is a complex process, which requires consider- 
ation of multiple parameters related to both - virtual models themselves, as well as the load affecting them $[4,7,8]$. Therefore, due to expected high quality of results and possibly the most accurate image of the processes actually occurring during the wheels interoperability, it is essential to investigate thoroughly the calculative process in order to acknowledge and standardize the procedure. The elaborated standardized and coherent methodology of conducting analysis of endurance tests would help to compare the results of the numerical measurements received for different types of cylindrical gears. Due to such specified practices even less experienced engineers would be able to conduct measurements with use of the finite element method.

In the present elaboration the process of preparation and conducting numerical calculation in the Abaqus software of dual-power path cylindrical gear was discussed. The analysed gear enables to transmit high power and obtain high gear ratio with relatively small dimensions. Their advantage is also the possibility of applying the internal load distribution, which is aimed to lower the single unit load of cooperating gear teeth. Their constructions are slightly more complicated than the solutions of single-power path gears, however they are much lighter with similar functioning parameters. These features enable to use these type of gears in ship power engines, in cars' automatic transmission gearboxes or in precision machine tools as an element of divisional device. Thanks to relatively small dimensions and its lightness they become increasingly interesting for engineers designing modern aviation constructions.

\section{Calculation model}

The first stage of the calculation process is the preparation of a virtual model accurate for a numerical analysis with the use of the FEM method. This model should ensure accurate execution of its discretisation, definition of boundary and initial conditions. What is more, the manner of attaching wheels and the conditions of gear elements interoperability will be presented and based upon this model. For the needs of the current analysis the complete virtual model of the discussed gear was created in the Inventor software.

The use of such detailed and accurate models for the needs of numerical calculations in the
Abaqus software would be burdensome and negatively impact the results quality. Therefore, on the basis of the complete three dimensions models there were created simplified, flat models, which are their cross-sections. Such a simplification was acceptable, due to the fact that the analysis was conducted on the cylindrical wheels with straight teeth, which do not change their outline on the whole width. Hence assumed models, based on the assumptions of the theory of flat deformed state, enable to analyse, enough accurately, the spatial constructions, such as cogged wheel $[2,6$, 9]. From the complete outline of particular wheels, only their fragments embracing over a dozen teeth, correspondingly to the scope of measurements were disengaged (fig. 1., fig. 2.). Moreover, this simplification allows to limit the time of calculations without deteriorating the quality, as in the examined range it does not induce changes concerning i.e. performance character, rigidness of the construction with view of genuine solution [5, 10]. The analysis was conducted only in the area of interoperability concerning several central cogs of each virtual model, which enable to eliminate the impact of boundary conditions on the cooperation of the wheels' teeth.

Additionally, the calculations concerning the dual-power path gear were carried out in two stages individually for a low-speed and high-speed degree. Nevertheless, the appropriate performance conditions were preserved by loading the active secondary wheels with torque calculated analytically on the basis of entry torque of primary stage and its gear ratio.

Every flat model of both examined types of gears imported into Abaqus software was discretized with the use of square, linear finite elements of CPS4R type. The most accurate division was defined on the toothed-wheel rims (fig. 1 and 2), as the main part of the analysis concerns the meshing [2].

The boundary conditions imposed on every model characteristically correspond into those from the real dual-power path gear. On the primary stage of the dual-power path gear the value of torque was equal $\mathrm{T} 1=1,592[\mathrm{Nm}]$, while on the second stage $-2,860[\mathrm{Nm}]$. The movement in the gear was executed by extortion of the passive wheels revolution of an angle 1,0 [rad]. It allows to trace interoperability of several cog pairs. Relatively low value of torque is the consequence of approval, 
for the calculations reason, of the assumption that plastic is the material for the wheels of all the gear types. This material was chosen, as the results of the current numerical analysis would be verified during the workplace tests with the use of real cogged wheels made from ABS. While defining the calculation models, the following basic features of ABS were assumed: Young's modulus 2400 [MPa] and Poisson's ratio 0,4.

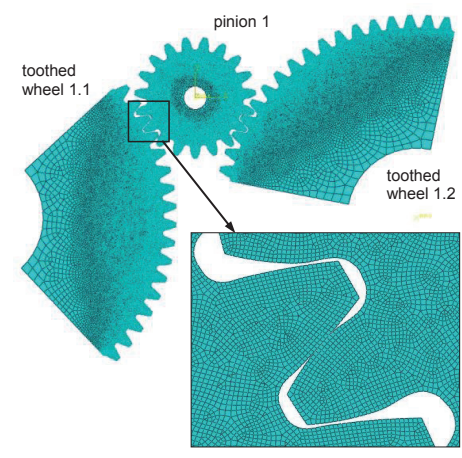

Fig. 1: Primary stage of the dual-power path gearing two-dimension model prepared for FEM calculations.

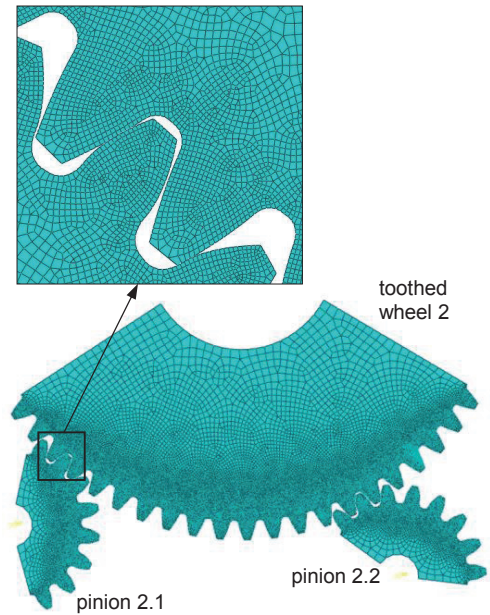

Fig. 2: Primary stage of the dual-power path gearing two-dimension model prepared for FEM calculations.

For the reason of accurately and completely prepared dual-power path gear models, numerical calculations were carried out in the solver of Abaqus software. The measurements concerning the models of each examined gear were conducted individually with the same parameters of the process of calculation as well as the representations themselves.

\section{Processing and analysis of the FEM calculations results}

During the calculations the appropriate solutions were obtained, which are presented as a distribution of stress reduced on the wheels models. The results of the particular calculation for the primary and secondary gear stage are presented on the pictures 3 and 5. Because of low clarity of the picture presenting the whole calculation model, magnified areas of the wheels meshing appears on the following pictures (fig. 4). The actual situation depicts the pinion interoperating with the tooth wheel 1.1 remaining in a dual-pair teeth contact. Simultaneously a single-pair teeth contact in the area of pinion's meshing with the tooth wheel 1.2 occurs.

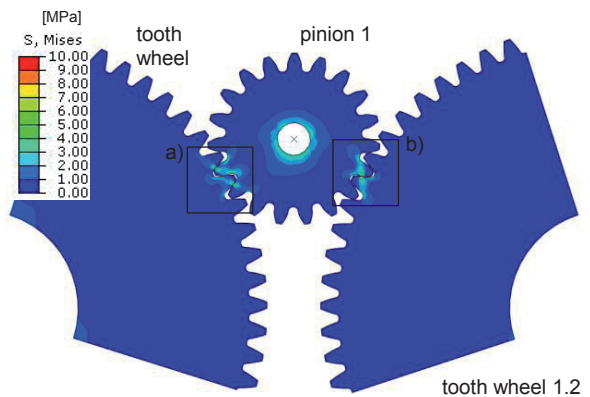

Fig. 3: Distribution of stress reduced on the primary stage wheels models of the dual-power path gearing.

The maximal value recorded on the model is 9,58 $[\mathrm{MPa}]$, whereas in the case of dual-pair teeth contact the maximal contact stress amounts to 8,47 [MPa]. Increased stress values may be observed as well on the teeth roots on the side opposite to the one where contact stress appear, however their level is much lower and their maximal values are up to 4 [MPa].

The appropriate torque causes the movement of the primary stage pinion, and through the interoperating teeth, the revolution of both cogwheels. Those wheels are fixed on the same shaft as the pinions of the secondary stage of the dual-power path gear.

It was assumed that the total value of a moment of torsion from the primary stage pinion is equally distributed onto both cogwheels interoperating with it. Therefore, the torque will be simultaneously transmitted by both secondary stage pinions onto the wheel connected with the output shaft of the secondary stage of a dual-power path gear. 
a)

b)
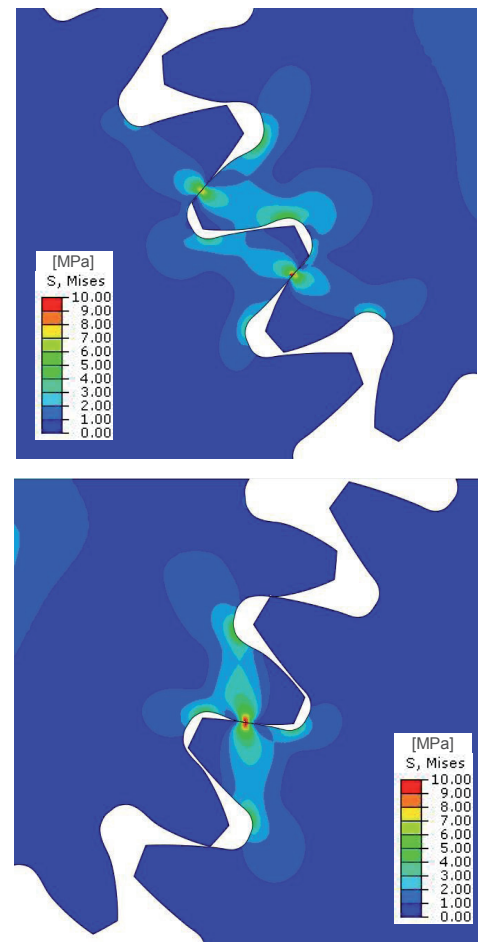

Fig. 4: Distribution of stress reduced in the areas of interoperability on the primary stage of a dual-power path gear for: a) tooth wheel 1.1, b) tooth wheel 1.2.

The results concerning the distribution of stress on wheel models of the secondary stage of a dualpower path gearing were presented on the picture 5.

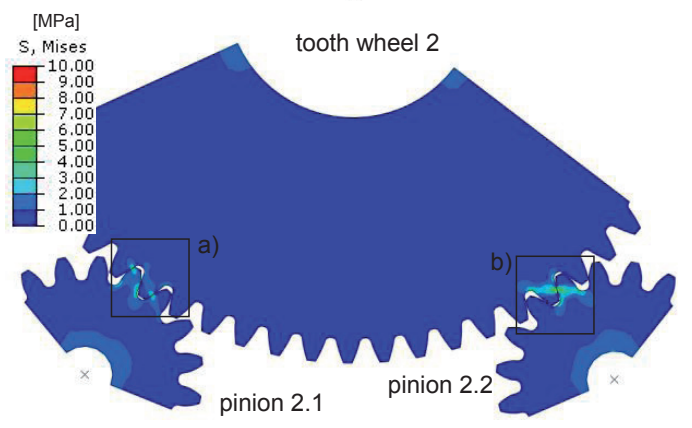

Fig. 5: Distribution of stress reduced on the secondary stage of a dual-power path gear.

Due to inadequate clarity of the results on the general view, magnification of their selected fragments including toothed rims in the meshing area were presented (fig. 6). The pinion 2.1 in period of time accurate for the demonstrated calculations remains in dual-pair teeth contact, while simultaneously the pinion 2.2 interoperates with the wheel 2 with only one pair of teeth involved.
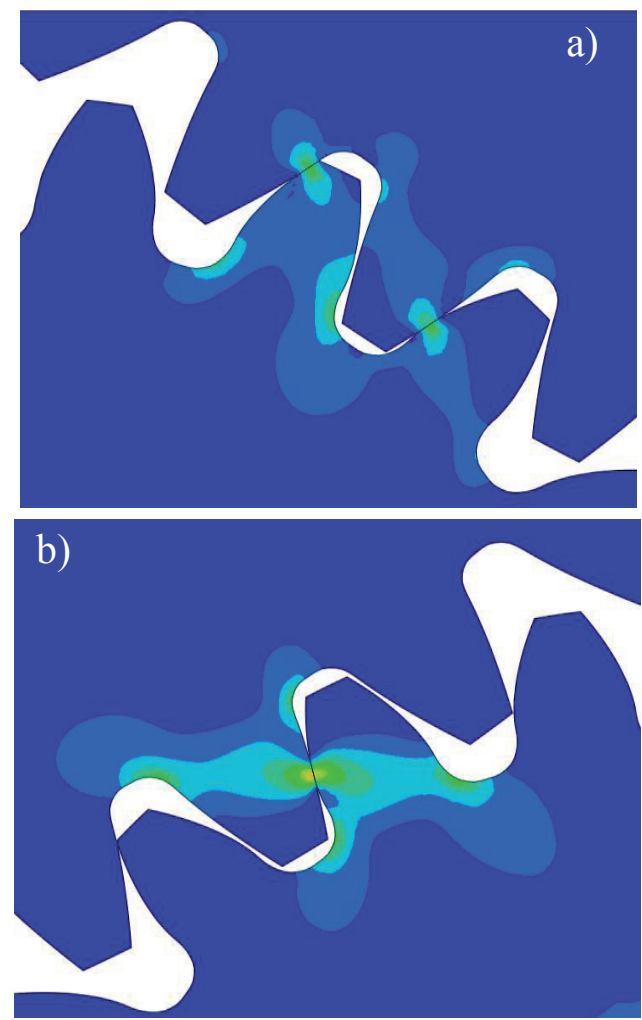

Fig. 6: Distribution of stress reduced in the areas of interoperability on the secondary stage of a dual-power path gearing for: a) pinion 2.1, b) pinion 2.2.

The distribution of stress for the above model looks very similar to the primary stage one of this gear. Moreover, the maximal values of contact stress on the lateral plane of the teeth are approximate - for the single-pair teeth contact equals 8,732 [MPa], while for the dual-pair teeth contact equals 7,42 [MPa].

In the case of a dual-power path gear, three wheels interoperates on each of its stages. Two of them revolves jointly, hence the description of the gear, from dual path of transmitting the workload. In order to avoid vibrations overlapping as well as mutual appearance of maximum load of the interoperating wheels, one of them was relocated to achieve displacement in the meshing phase.

\section{Conclusion}

The analyses of the dual-power path gear allow 
to trace the whole process and to determine the procedures methodology in case of strength calculations with application of the FEM method.

All of the above results for the gears made from ABS remained in the range of acceptable values for the approved material. The distributions of contact and bending stress presented hereinabove are compatible with the ones known from the literature. The values of the maximum stress for equally planetary gear and both stages of dual-power path gear, reached similar level. Described procedures as far as the preparation and calculation stages are concerned, and sequentially their appropriate presentation and analysis may be accepted as the recommended scheme to follow during successive measurements of similar mechanical gears.

The calculations were carried out in a hundred measurement stages, enabling to trace, in a very accurate manner, the interoperability of particular cogs in different phases of meshing. By means of the above, the most characteristic solutions were found, which were depicted as distributions of stress on the wheels models. The highest values of stress appeared in the place of contact of the interoperating teeth lateral surfaces. What is more, the bending stress values of the teeth roots remaining in the contact were outstanding, however much lower than the contact stress rates.

The Abaqus software enables to carry out highly complicated analyses $[1,3,8]$, as well as to automatize multiple procedures of calculation results processing and to present them in an intelligible form expected for its further interpretation.

\section{References}

[1] Baláž M., Mohamad Al Ali: Simulation of experimental test using 3d modelling, INTERNATIONAL JOURNAL OF INTERDISCIPLINARITY IN THEORY AND PRACTICE ITPB - NR: $1 / 2013$

[2] Bąk R., Burczyński T.: Wytrzymałość materiałów z elementami ujęcia komputerowego, Wydawnictwa Naukowo-Techniczne, Warszawa 2001.

[3] Budzik G., Kozik B., Pacana J.: Determining of model similarity for flexsplaine of harmonic drive with the use of FEM and extensometer method, Journal of KONES Powertrain and Transport, Vol. 16, No 2 (2009),

[4] Daneshjo. N.: Computers Modelling and Simulation, Adv. Mat. Res. 463/64 (2012).

[5] Jaśkiewicz Z., Wąsiewski A.: Przekładnie walcowe, Tom I. Geometria, wytrzymałość, dokładność wykonania, WKŁ,
Warszawa 1992

[6] Kleiber M.: Komputerowe metody mechaniki ciał stałych, PWN, Warszawa 1995

[7] Mijał M., Kudasik T.: Wyznaczanie rozkładu naprężeń w kołach podatnych zębatych przekładni falowych, Zeszyty Naukowe Politechniki Rzeszowskiej nr 232, Mechanika z. 69 (2006).

[8] Mohamad Al Ali: Analysis of plastic zones during the welding process, INTERNATIONAL JOURNAL OF INTERDISCIPLINARITY IN THEORY AND PRACTICE ITPB - NR.: 3/2014.

[9] Rakowski G., Kacprzyk Z.: Metoda Elementów Skończonych w Mechanice Konstrukcji, Oficyna Wydawnicza Politechniki Warszawskiej, Warszawa 2005.

[10] Rusiński E., Czmochowski J., Smolnicki T.: Zaawansowana metoda elementów skończonych w konstrukcjach nośnych, Oficyna Wydawnicza Politechniki Wrocławskiej, Wrocław 2000.

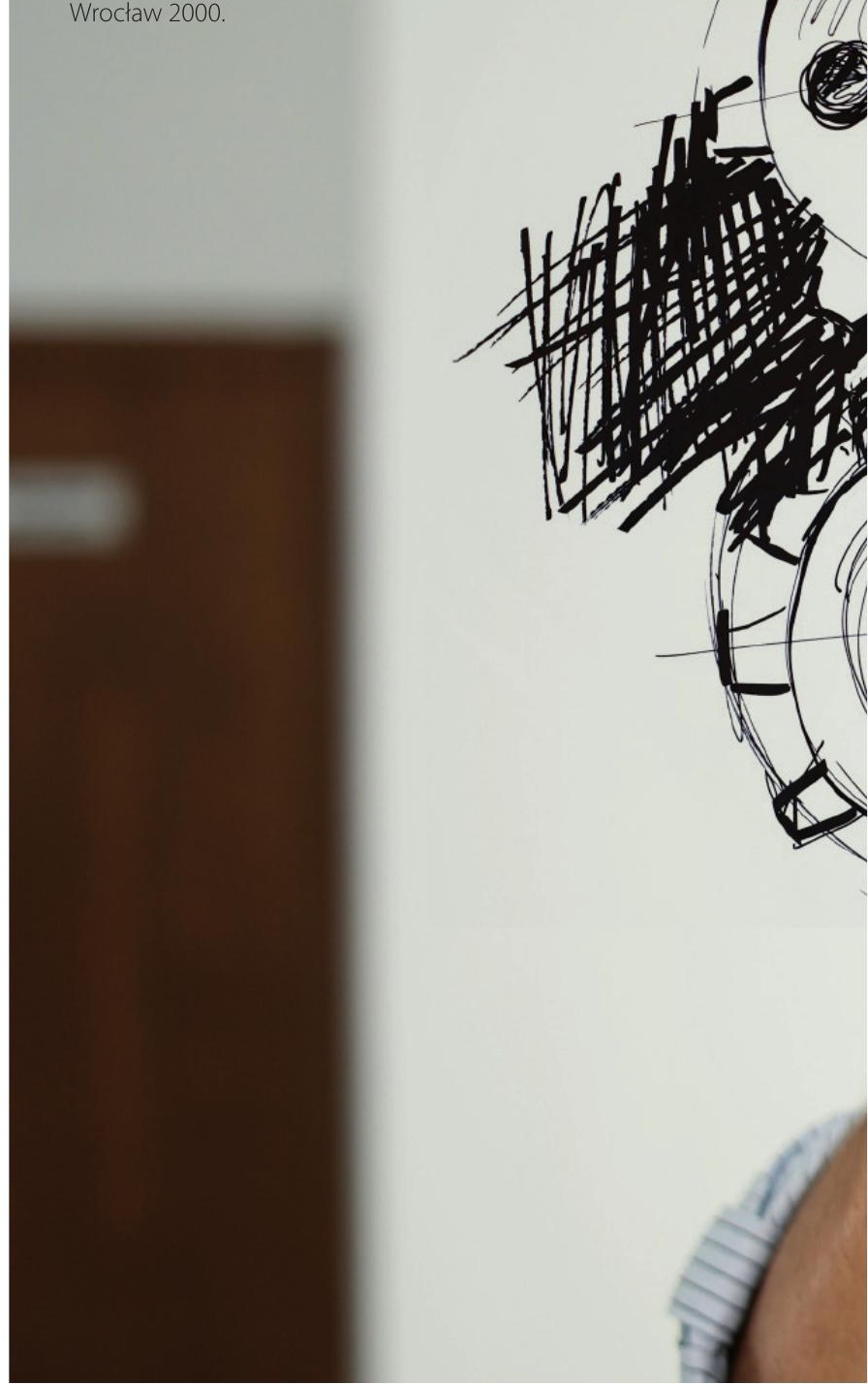




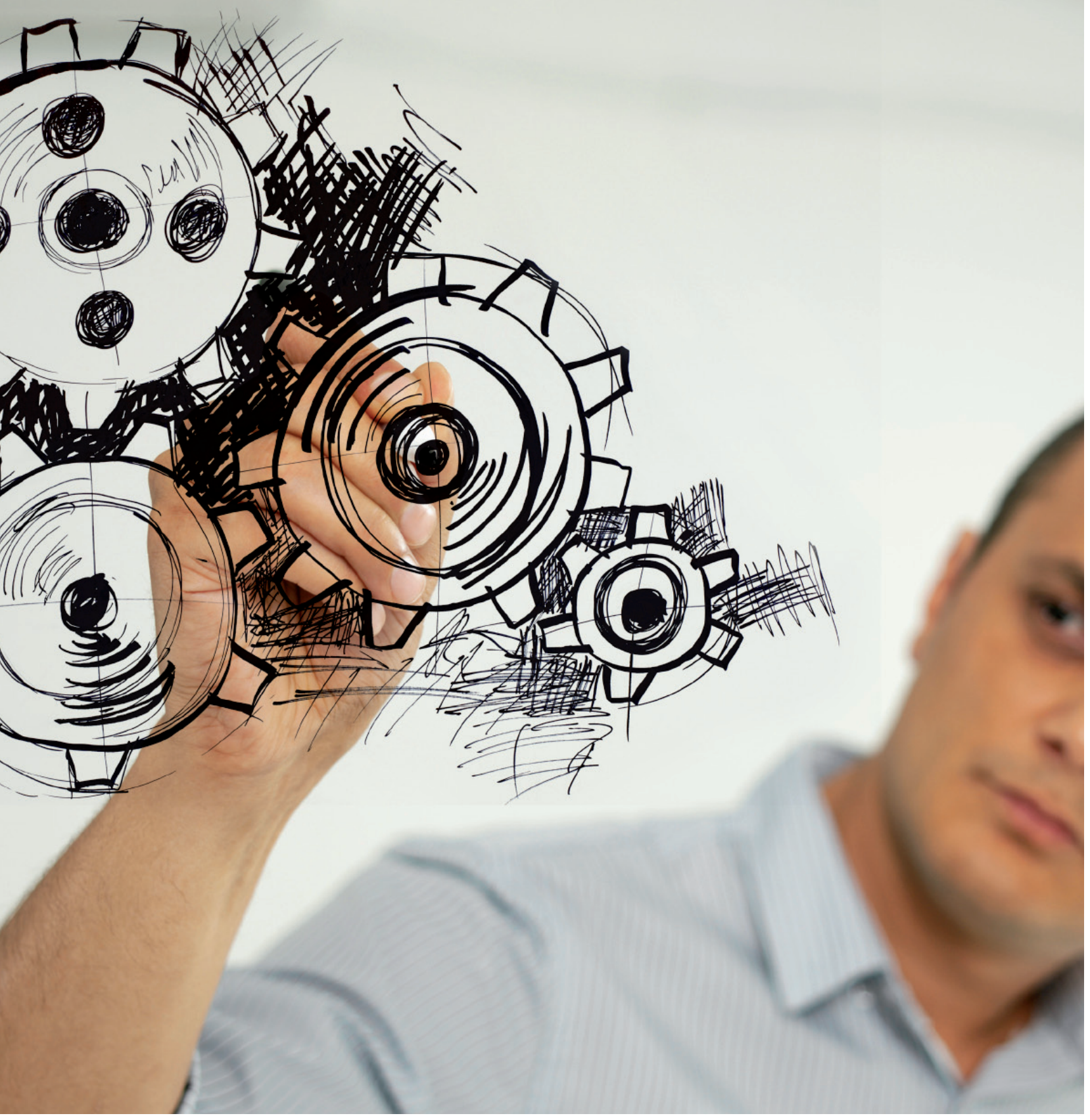

